\title{
Treatment Patterns Among Patients with Psoriatic Arthritis Treated with a Biologic in the United States: Descriptive Analyses from an Administrative Claims Database
}

\author{
Jessica A. Walsh, MD; Oluwakayode Adejoro, MD, MPH; Benjamin Chastek, MS; \\ Jacqueline B. Palmer, PharmD; and Peter Hur, PharmD, MBA
}

\begin{abstract}
BACKGROUND: In patients with psoriatic arthritis (PsA), limited data exist regarding patterns of biologic therapy use.

OBJECTIVE: To examine treatment patterns and therapy modifications in U.S. patients with PsA receiving a tumor necrosis factor inhibitor (TNFi) or an anti-interleukin (IL)-12/23 inhibitor.

METHODS: Adults with PsA who newly initiated a biologic therapy (index biologic) between January 1, 2013, and January 31, 2015, were included from the Optum Research Database. Biologic therapies comprised those that were approved by the FDA for the treatment of PsA at the time of the study initiation (adalimumab, certolizumab pegol, etanercept, golimumab, infliximab, or ustekinumab). Outcomes included adherence, persistence, and discontinuation of the index biologic; initiation of adjunctive medications (nonbiologics, including those commonly used for pain and/or inflammation); and dose escalation of the index biologic during the 12-month follow-up period.
\end{abstract}

RESULTS: Of the 1,235 patients included, $52.5 \%$ were female, and mean (SD) age was 50.3 (12.1) years. The mean (SD) duration of persistence with a newly initiated index biologic (etanercept [48.1\%], adalimumab [24.0\%], infliximab [10.4\%], golimumab [8.3\%], ustekinumab [7.2\%], or certolizumab pegol [2.0\%]) was 246 (128) days; $44.5 \%$ of patients persisted with the index biologic for $\geq 12$ months. During the 12-month follow-up period, $22.9 \%$ of patients switched to a different biologic, $26.8 \%$ discontinued without switching or restarting, and $5.8 \%$ discontinued and restarted the index biologic. of the 1,010 patients who persisted with the index biologic for $>90$ days, $45.6 \%$ received $\geq 1$ adjunctive medication during the period from 90 days after the index date to the end of persistence or 12 months. The most commonly initiated adjunctive medications were corticosteroids (22.0\%), opioids (17.1\%), and nonsteroidal anti-inflammatory drugs (12.9\%). Overall, $9.6 \%$ of patients had a dose escalation of the index biologic in the immediate 12-month post-index period.

CONCLUSIONS: This real-world study of treatment patterns for PsA, which used a large U.S. claims database, demonstrated that the majority of patients with PSA discontinued their index biologic (TNFi or anti-IL-12/23 inhibitor) before 12 months. Nearly half of patients initiated an adjunctive medication, many of which were pain and conventional anti-inflammatory medications.

J Manag Care Spec Pharm. 2018;24(7):623-31

Copyright $\odot 2018$, Academy of Managed Care Pharmacy. All rights reserved.

\section{What is already known about this subject}

Treatment persistence is important for achieving optimal outcomes in patients with psoriatic arthritis (PsA) receiving biologic therapy.

Updated estimates are needed of treatment adherence and persistence that reflect new therapies approved for PsA, as well as studies of dose escalation of biologic therapy and adjunctive modifications.

\section{What this study adds}

The majority of patients with PsA (56\%) discontinued their index biologic (either a tumor necrosis factor inhibitor [TNFi] or an anti-interleukin [IL]-12/23 inhibitor) before 12 months; the mean duration of persistence was approximately 8 months.

Nearly half (45\%) of the patients initiated an adjunctive medication, many of which were pain and anti-inflammatory medications. Outcomes from this study of real-world treatment patterns for PsA from a single U.S. claims database suggest that in this population of patients with PsA, additional options for concomitant therapies or alternatives to TNFis and anti-IL-12/23 inhibitors may be important.

$\mathrm{P}$ soriatic arthritis (PsA) is a chronic, immune-mediated, rheumatic disease that affects joints, tendons, skin, and nails and causes pain, functional limitations, and irreversible joint damage..$^{1-3}$ Patients with PsA may have varied clinical presentations, including swollen joints, enthesitis, dactylitis, psoriatic skin lesions, and axial disease. ${ }^{4}$ In addition, PsA can cause joint damage and destruction, which may result in deformities. ${ }^{5}$ Several comorbidities are also associated with PsA, including cardiovascular disease, hypertension, metabolic syndrome, liver disease, obesity, depression, and anxiety, and PsA is associated with a decreased quality of life., ${ }^{3,6-10}$ The prevalence of PsA in the United States is estimated to be $0.10 \%$ to $0.25 \%{ }^{3}$

Treatment recommendations are based on clinical domains, degree of joint and skin involvement, and patient quality of life. Initial treatment of mild PsA may include topical therapies and nonsteroidal anti-inflammatory drugs (NSAIDs). ${ }^{4,11,12}$ For patients with moderate to severe psoriatic activity or poor 
prognostic indicators, synthetic disease-modifying antirheumatic drugs (DMARDs) and biologic DMARDs are recommended. ${ }^{4,12,13}$ Biologics approved for the treatment of PsA include the tumor necrosis factor inhibitors (TNFis) adalimumab, certolizumab pegol, etanercept, golimumab, and infliximab; ${ }^{14-21}$ the human anti-interleukin (IL)-12/23 monoclonal antibody ustekinumab, ${ }^{22}$ the selective T-cell costimulation modulator abatacept, ${ }^{23,24}$ approved by the U.S. Food and Drug Administration (FDA) for the treatment of PsA in 2017; and the anti-IL-17A monoclonal antibodies secukinumab and ixekizumab, ${ }^{25-28}$ which were approved by the FDA for the treatment of PsA in 2016 and 2017, respectively.

Treatment persistence is important for achieving optimal outcomes in patients with PsA who are receiving biologic therapy. ${ }^{29}$ Although standard dosing of biologic therapies is effective for many patients, dose escalations, adjunctive medications, and switching between biologic therapies are often necessary for inadequately controlled pain and inflammation. ${ }^{4,30-33}$ However, real-world studies examining biologic therapy use in U.S. patients with PsA are limited, especially those involving treatment modifications. Recently published studies have examined biologic therapy treatment patterns, ${ }^{32,34-38}$ but updated estimates of treatment adherence and persistence that reflect new therapies approved for PsA, and studies of dose escalation of biologic therapy and adjunctive medications, are still needed. The objective of this study was to describe treatment patterns and therapy modifications in U.S. patients who newly initiated an approved FDA biologic therapy for PsA at the time of the study (either a TNFi or an anti-IL-12/23 inhibitor).

\section{Methods}

\section{Data Source}

This retrospective, observational study used U.S. administrative claims data obtained from the Optum Research Database (ORD) between January 1, 2012, and April 30, 2016. The ORD includes commercial and Medicare Advantage health plan members. In 2015, data were available for approximately 13.5 million individuals with both medical and pharmacy benefit coverage. Claims for pharmacy services are submitted electronically by the pharmacy when prescriptions are filled. Pharmacy claims data include National Drug Code numbers, dosage form, strength, fill date, days of supply, and cost information. Because this study used only de-identified patient records and did not involve the collection, use, or transmittal of individually identifiable data, it is not subject to the U.S. Department of Health and Human Services regulation for the protection of human subjects.

\section{Study Design and Patient Selection}

This study included patients aged $\geq 18$ years who initiated therapy with an FDA-approved biologic for PsA between January 1 , 2013, and January 31, 2015. Patients with PsA were identified using the International Classification of Diseases, Ninth/Tenth Revision, Clinical Modification (ICD-9/10-CM) codes (ICD-9-CM code 696.0; ICD-10-CM codes L40.50, L40.51, L40.52, L40.53, L40.54, and L40.59). Patients had to have $\geq 2$ non-rule-out diagnoses of PsA $\geq 30$ days apart during the 12 months before the index date (baseline period) through 12 months after the index date, with the first diagnosis occurring during the baseline period or on the index date. The index date was defined as the date of first pharmacy fill or medical infusion of the index biologic. Only patients with no evidence of biologic use in the prior 12 months were included. Patients who had claims for $\geq 2$ different biologics on the same day during the 12-month baseline period through the 15-month follow-up period were excluded.

Patients had to be continuously enrolled in a commercial or Medicare Advantage health plan for 12 months before (baseline period) and 15 months after (follow-up period) the index date. The 12-month baseline period was used to assess patient characteristics and demographics. In the 15-month followup period, only the first 12 months post-index were used to assess outcomes (including biologic persistence, discontinuation, switching, dose escalation, and initiation of adjunctive medications), and the last 3 months were allowed for time to observe gaps in therapy following fills received at the end of the 12-month follow-up period (Appendix A, available in online article). To reduce confounding, the addition of adjunctive medications and dose escalations were identified only in patients who persisted with their index biologic for $>90$ days.

The efficacy of biologics is generally not assessed in the first 3 months because of the time needed to see a clinical response in some patients; therefore, the addition of adjunctive medications or dose escalations in the first 3 months may not be related to lack of efficacy. The add-on period was defined as the period from 90 days after the index date to either the end of persistence or 12 months post-index (whichever came first).

\section{Study Outcomes}

Patient characteristics recorded at the index date included age, sex, geographic region, and insurance type. A baseline comorbidity score (Quan-Charlson Comorbidity Index) based on the presence of diagnosis codes on medical claims in the baseline period was calculated, ${ }^{39,40}$ and comorbid conditions were recorded. Baseline comorbid conditions were defined using the Quan-Charlson Comorbidity Index.

The biologic treatment was identified on the index date, and the biologics approved by the FDA for the treatment of PsA at the start of the study included adalimumab, certolizumab pegol, etanercept, golimumab, infliximab, and ustekinumab. Adherence and persistence were measured in the follow-up period using claims for the index biologic, inclusive of fills or infusions on the index date. Adherence was measured as the proportion of days covered (PDC) in 12 months, calculated as the number of days covered by prescription claims for the 
Treatment Patterns Among Patients with Psoriatic Arthritis Treated with a Biologic in the United States: Descriptive Analyses from an Administrative Claims Database

\section{TABLE 1 Baseline Demographic Characteristics, Clinical Characteristics, and Medications}

\begin{tabular}{|c|c|c|c|c|c|c|c|}
\hline \multirow[b]{2}{*}{ Characteristic } & \multirow[b]{2}{*}{$\begin{array}{c}\text { Total } \\
(\mathrm{N}=1,235)\end{array}$} & \multicolumn{4}{|c|}{ TNFi SC } & \multirow{2}{*}{$\begin{array}{l}\text { TNFi IV } \\
\text { Infliximab } \\
(\mathbf{n}=129)\end{array}$} & \multirow{2}{*}{\begin{tabular}{|c} 
Anti-IL-12/23 \\
SC \\
$\begin{array}{c}\text { Ustekinumab } \\
(\mathrm{n}=89)\end{array}$
\end{tabular}} \\
\hline & & $\begin{array}{l}\text { Adalimumab } \\
\quad(\mathrm{n}=296)\end{array}$ & $\begin{array}{c}\text { Certolizumab } \\
\text { pegol } \\
(\mathbf{n}=25)\end{array}$ & $\begin{array}{l}\text { Etanercept } \\
(\mathrm{n}=594)\end{array}$ & $\begin{array}{l}\text { Golimumab } \\
(\mathrm{n}=102)\end{array}$ & & \\
\hline Age, years, mean (SD) & $50.3(12.1)$ & $49.6(12.3)$ & $49.5(11.4)$ & $50.2(11.7)$ & $47.3(10.8)$ & $53.4(13.2)$ & $51.7(12.7)$ \\
\hline Female, n (\%) & $648(52.5)$ & $147(49.7)$ & $17(68.0)$ & $301(50.7)$ & $55(53.9)$ & $81(62.8)$ & $47(52.8)$ \\
\hline $\begin{array}{l}\text { Baseline Quan-Charlson Comorbidity } \\
\text { Index score, mean (SD) }\end{array}$ & $0.73(1.15)$ & $0.72(1.18)$ & $1.60(1.53)$ & $0.67(1.05)$ & $0.55(0.80)$ & $0.98(1.44)$ & $0.75(1.27)$ \\
\hline \multicolumn{8}{|l|}{ Quan-Charlson comorbidities, n (\%) } \\
\hline Rheumatologic disease & $299(24.2)$ & $76(25.7)$ & $14(56.0)$ & $133(22.4)$ & $26(25.5)$ & $40(31.0)$ & $10(11.2)$ \\
\hline Chronic pulmonary disease & $162(13.1)$ & $33(11.2)$ & $3(12.0)$ & $83(14.0)$ & $11(10.8)$ & $17(13.2)$ & $15(16.8)$ \\
\hline Liver disease, mild & $100 \quad(8.1)$ & $24 \quad(8.1)$ & $7(28.0)$ & $40 \quad(6.7)$ & $8 \quad(7.8)$ & $15(11.6)$ & $6 \quad(6.7)$ \\
\hline Renal disease & $45 \quad(3.6)$ & $8 \quad(2.7)$ & $2(8.0)$ & $21 \quad(3.5)$ & $2(2.0)$ & $6 \quad(4.6)$ & $6 \quad(6.7)$ \\
\hline Diabetes, with chronic complications & $45 \quad(3.6)$ & $8 \quad(2.7)$ & $1 \quad(4.0)$ & $26 \quad(4.4)$ & $1 \quad(1.0)$ & $3(2.3)$ & $6 \quad(6.7)$ \\
\hline \multicolumn{8}{|l|}{ U.S. region, $\mathrm{n}(\%)$} \\
\hline Northeast & $155(12.6)$ & $58(19.6)$ & $2(8.0)$ & $58 \quad(9.8)$ & $5 \quad(4.9)$ & $22(17.1)$ & $10(11.2)$ \\
\hline Midwest & $306(24.8)$ & $65(22.0)$ & $7(28.0)$ & $146(24.6)$ & $28(27.5)$ & $37(28.7)$ & $23(25.8)$ \\
\hline South & $608(49.2)$ & $129(43.6)$ & $14(56.0)$ & $311(52.4)$ & $55(53.9)$ & $58(45.0)$ & $41(46.1)$ \\
\hline West & $166(13.4)$ & $44(14.9)$ & $2(8.0)$ & $79(13.3)$ & $14(13.7)$ & $12 \quad(9.3)$ & $15(16.9)$ \\
\hline \multicolumn{8}{|l|}{ Insurance type, n (\%) } \\
\hline Commercial & $1,059(85.7)$ & $249(84.1)$ & $21(84.0)$ & $519(87.4)$ & $96(94.1)$ & $100(77.5)$ & $74(83.1)$ \\
\hline Medicare & $176(14.3)$ & 47 (15.9) & $4(16.0)$ & $75(12.6)$ & $6 \quad(5.9)$ & $29(22.5)$ & $15(16.9)$ \\
\hline \multicolumn{8}{|l|}{ Medication, n (\%) } \\
\hline Any medication & 1,132 (91.7) & $275(92.9)$ & $24(96.0)$ & $544(91.6)$ & $96(94.1)$ & $118(91.5)$ & $75(84.3)$ \\
\hline Biologics & $182(14.7)$ & $31(10.5)$ & $2(8.0)$ & $82(13.8)$ & $30(29.4)$ & $20(15.5)$ & $17(19.1)$ \\
\hline Corticosteroid & $756(61.2)$ & $183(61.8)$ & $17(68.0)$ & $366(61.6)$ & $69(67.6)$ & $74(57.4)$ & $47(52.8)$ \\
\hline Opioid & $600(48.6)$ & $153(51.7)$ & $17(68.0)$ & $276(46.5)$ & $49(48.0)$ & $65(50.4)$ & $40(44.9)$ \\
\hline NSAID & $663(53.7)$ & $167(56.4)$ & $11(44.0)$ & $326(54.9)$ & $59(57.8)$ & $65(50.4)$ & $35(39.3)$ \\
\hline csDMARDa & $632(51.2)$ & $154(52.0)$ & $14(56.0)$ & $293(49.3)$ & $62(60.8)$ & $76(58.9)$ & $33(37.1)$ \\
\hline Antidepressant & $381(30.8)$ & $73(24.7)$ & $13(52.0)$ & $180(30.3)$ & $36(35.3)$ & $55(42.6)$ & $24(27.0)$ \\
\hline Anxiolytic & $289(23.4)$ & $69(23.3)$ & $6(24.0)$ & $139(23.4)$ & $22(21.6)$ & $33(25.6)$ & $20(22.5)$ \\
\hline Topical analgesic & $84 \quad(6.8)$ & $22 \quad(7.4)$ & $3(12.0)$ & $36 \quad(6.1)$ & $6 \quad(5.9)$ & $13(10.1)$ & $4 \quad(4.5)$ \\
\hline Sleep aid & $154(12.5)$ & $32(10.8)$ & $3(12.0)$ & $73(12.3)$ & $13(12.7)$ & $20(15.5)$ & $13(14.6)$ \\
\hline tsDMARD $^{b}$ & $9 \quad(0.7)$ & $1 \quad(0.3)$ & $0 \quad(0.0)$ & $2(0.3)$ & $1 \quad(1.0)$ & $2 \quad(1.5)$ & $3 \quad(3.4)$ \\
\hline \multicolumn{8}{|c|}{$\begin{array}{l}\text { ancluded auranofin, aurothioglucose, azathioprine, cyclosporine, gold sodium, hydroxychloroquine, leflunomide, methotrexate, and sulfasalazine. } \\
\text { bIncluded apremilast and tofacitinib. } \\
\text { cSDMARD = conventional synthetic disease-modifying antirheumatic drug; IL=interleukin; IV=intravenous; NSAID = nonsteroidal anti-inflammatory drug; } \\
S C=\text { subcutaneous; SD = standard deviation; TNFi= tumor necrosis factor inhibitor; tsDMARD = targeted synthetic disease-modifying antirheumatic drug. }\end{array}$} \\
\hline
\end{tabular}

index biologic divided by 365 days. Persistence was measured as the number of days from the index date to the date of discontinuation of the index biologic or switching to a different biologic. Discontinuation was defined as a gap in therapy of $>90$ days based on clinical expert opinion; the date of discontinuation was defined by the run-out-of-days supply of the last prescription filled before the gap in therapy.

Postpersistence treatment patterns were evaluated for all patients who were not persistent for 12 months and were classified as (a) discontinuing the index therapy without switching or restarting; (b) discontinuing and restarting the index therapy; and (c) switching to a different biologic. Among patients who switched to a different biologic, the biologic that a patient was switched to was identified, and the number of days from the index date to the switch date (defined as the earliest claim that indicates a switch after the index date) was calculated.

For patients who were persistent with the index biologic for $>90$ days, initiation of adjunctive medications and dose escalation of the index biologic were identified from 90 days after the index date until the end of persistence or 12 months post-index (add-on period). Patients had to have no claims for the adjunctive medication during the first 90 days after the index date for it to be considered an adjunctive medication. The adjunctive medications included conventional synthetic DMARDs (csDMARDs), NSAIDs, opioids, corticosteroids, antidepressants, anxiolytics, targeted synthetic DMARDs, sleep aids, and topical 
Treatment Patterns Among Patients with Psoriatic Arthritis Treated with a Biologic in the United States: Descriptive Analyses from an Administrative Claims Database

TABLE 2 Adherence and Persistence with Index Biologic Therapies and Postpersistence Treatment Patterns

\begin{tabular}{|c|c|c|c|c|c|c|c|}
\hline & \multirow[b]{2}{*}{$\begin{array}{c}\text { Total } \\
(\mathrm{N}=1,235)\end{array}$} & \multicolumn{4}{|c|}{ TNFi SC } & \multirow{2}{*}{$\begin{array}{c}\text { TNFi IV } \\
\begin{array}{c}\text { Infliximab } \\
(\mathrm{n}=129)\end{array}\end{array}$} & \multirow{2}{*}{$\begin{array}{l}\text { Anti-IL-12/23 } \\
\text { SC } \\
\begin{array}{c}\text { Ustekinumab } \\
(\mathrm{n}=89)\end{array}\end{array}$} \\
\hline & & $\begin{array}{l}\text { Adalimumab } \\
(\mathbf{n}=296)\end{array}$ & $\begin{array}{c}\text { Certolizumab } \\
\text { pegol } \\
(\mathrm{n}=25)\end{array}$ & $\begin{array}{l}\text { Etanercept } \\
(\mathrm{n}=594)\end{array}$ & $\begin{array}{l}\text { Golimumab } \\
(\mathrm{n}=102)\end{array}$ & & \\
\hline \multicolumn{8}{|l|}{ Proportion of days covered ${ }^{a}$} \\
\hline Mean (SD) & $0.59(0.30)$ & $0.56(0.30)$ & $0.51(0.30)$ & $0.57(0.30)$ & $0.61(0.28)$ & $0.77(0.28)$ & $0.66(0.28)$ \\
\hline Median (IQR) & $\begin{array}{c}0.66 \\
(0.31-0.88) \\
\end{array}$ & $\begin{array}{c}0.59 \\
(0.24-0.86) \\
\end{array}$ & $\begin{array}{c}0.57 \\
(0.15-0.76) \\
\end{array}$ & $\begin{array}{c}0.58 \\
(0.30-0.85) \\
\end{array}$ & $\begin{array}{c}0.71 \\
(0.35-0.84) \\
\end{array}$ & $\begin{array}{c}0.90 \\
(0.61-0.99) \\
\end{array}$ & $\begin{array}{c}0.75 \\
(0.46-0.91) \\
\end{array}$ \\
\hline \multicolumn{8}{|l|}{ Duration of persistence, days } \\
\hline Mean (SD) & $246 \quad(128)$ & $237 \quad(131)$ & $207(146)$ & $238(128)$ & $261 \quad(126)$ & $293(109)$ & $261 \quad(129)$ \\
\hline Median (IQR) & $303(117-365)$ & $280(104-365)$ & $203(50-365)$ & $260(111-365)$ & $365(140-365)$ & $365(224-365)$ & $365(120-365)$ \\
\hline \multicolumn{8}{|l|}{ Persistence, patients, $\mathbf{n}(\%)^{b}$} \\
\hline $\begin{array}{l}\text { Persisted with index biologic for } \\
\geq 90 \text { days }\end{array}$ & $1,010(82.0)$ & $236(79.7)$ & $16(64.0)$ & $476(80.1)$ & $85(83.3)$ & $121(93.8)$ & $76(85.4)$ \\
\hline $\begin{array}{l}\text { Persisted with index biologic for } \\
12 \text { months }\end{array}$ & $549(44.5)$ & $126(42.6)$ & $8(32.0)$ & $239(40.2)$ & $52(51.0)$ & $79(61.2)$ & $45(50.6)$ \\
\hline \multicolumn{8}{|c|}{ Postpersistence treatment patterns, patients, $\%^{\mathrm{c}}$} \\
\hline $\begin{array}{l}\text { Discontinued index biologic without } \\
\text { restart or switch }\end{array}$ & $331(26.8)$ & $80(27.0)$ & $6(24.0)$ & $168(28.3)$ & $20(19.6)$ & $30(23.3)$ & $27(30.3)$ \\
\hline Discontinued and restarted biologic & $72 \quad(5.8)$ & $19 \quad(6.4)$ & $4(16.0)$ & $30 \quad(5.0)$ & $4 \quad(3.9)$ & $5 \quad(3.9)$ & $10(11.2)$ \\
\hline $\begin{array}{l}\text { Switched from index biologic to a } \\
\text { different biologic }\end{array}$ & $283(22.9)$ & $71(24.0)$ & $7(28.0)$ & $157(26.4)$ & $26(25.5)$ & $15(11.6)$ & $7 \quad(7.9)$ \\
\hline Mean time to switche days $(95 \% \mathrm{CI})$ & $\begin{array}{c}177.4 \\
(166.6-188.2) \\
\end{array}$ & $\begin{array}{c}179.9 \\
(158.2-201.5) \\
\end{array}$ & $\begin{array}{c}141.6 \\
(62.3-220.8) \\
\end{array}$ & $\begin{array}{c}176.6 \\
(162.1-191.2) \\
\end{array}$ & $\begin{array}{c}183.0 \\
(142.6-191.2) \\
\end{array}$ & $\begin{array}{c}168.6 \\
(120.0-217.2) \\
\end{array}$ & $\begin{array}{c}202.3 \\
(104.2-300.4) \\
\end{array}$ \\
\hline \multicolumn{8}{|c|}{$\begin{array}{l}\text { aProportion of days covered was defined as the number of days covered by prescription claims for the index biologic divided by } 365 \text { (follow-up period). } \\
\text { bDuring the 12-month follow-up period. } \\
\text { 'Among patients who discontinued during the 12-month follow-up period. } \\
{ }^{d} \text { Includes patients who discontinued the index biologic and then switched to a different biologic. } \\
\text { eAmong patients who switched biologic therapies. } \\
C I=\text { confidence interval; IL=interleukin; IQR=interquartile range; IV=intravenous; SC=subcutaneous; SD=standard deviation; TNFi=tumor necrosis factor inhibitor. }\end{array}$} \\
\hline
\end{tabular}

analgesics. Dose escalation was defined as a patient receiving a dose $>110 \%$ of the reference dose from the product label for $\geq 90$ continuous or intermittent days. The time-to-dose escalation was measured as the number of days from the index date until the 90th day with a dose $>110 \%$ of the reference dose.

\section{Statistical Analyses}

All data were analyzed descriptively. Patient-level analyses included baseline demographics, number of patients initiating each biologic, and number of patients who discontinued or switched treatments. Subgroup analyses by index biologic reported the mean (standard deviation [SD]) duration of time patients persisted on the index biologic, time to switch to a different biologic, number of patients with dose escalation of the index biologic, and number of patients who initiated adjunctive medications.

\section{Results}

\section{Demographics and Baseline Characteristics}

A total of 1,235 patients who newly initiated a biologic therapy were included (Appendix B, available in online article). Approximately half of the patients ( $n=594,48.1 \%)$ initiated etanercept, followed by adalimumab ( $n=296,24.0 \%)$, infliximab $(n=129,10.4 \%)$, golimumab $(n=102,8.3 \%)$, ustekinumab ( $n=89,7.2 \%)$, and certolizumab pegol $(n=25$, $2.0 \%$ ) as their index biologic (Table 1). Of the total patients, the mean (SD) age was 50.3 (12.1) years, and 52.5\% were women. The mean (SD) Quan-Charlson Comorbidity Index score was 0.73 (1.15) at baseline. Patients initiating certolizumab pegol as their index biologic had the highest mean (SD) Quan-Charlson score (1.60 [1.53]). The overall most common baseline QuanCharlson comorbidities were rheumatologic disease (24.2\%) and chronic pulmonary disease (13.1\%).

\section{Adherence, Persistence, and Postpersistence Treatment Patterns}

The mean (SD) and median (interquartile range [IQR]) PDC for biologics evaluated were 0.59 (0.30) and 0.66 (0.31-0.88), respectively (Table 2). Patients who initiated infliximab had the highest mean (SD) PDC (0.77 [0.28]) and patients who initiated certolizumab pegol had the lowest PDC (0.51 [0.30]). The mean (SD) and median (IQR) persistence with the index biologic were 246 (128) days and 303 (117-365) days, respectively. Patients 


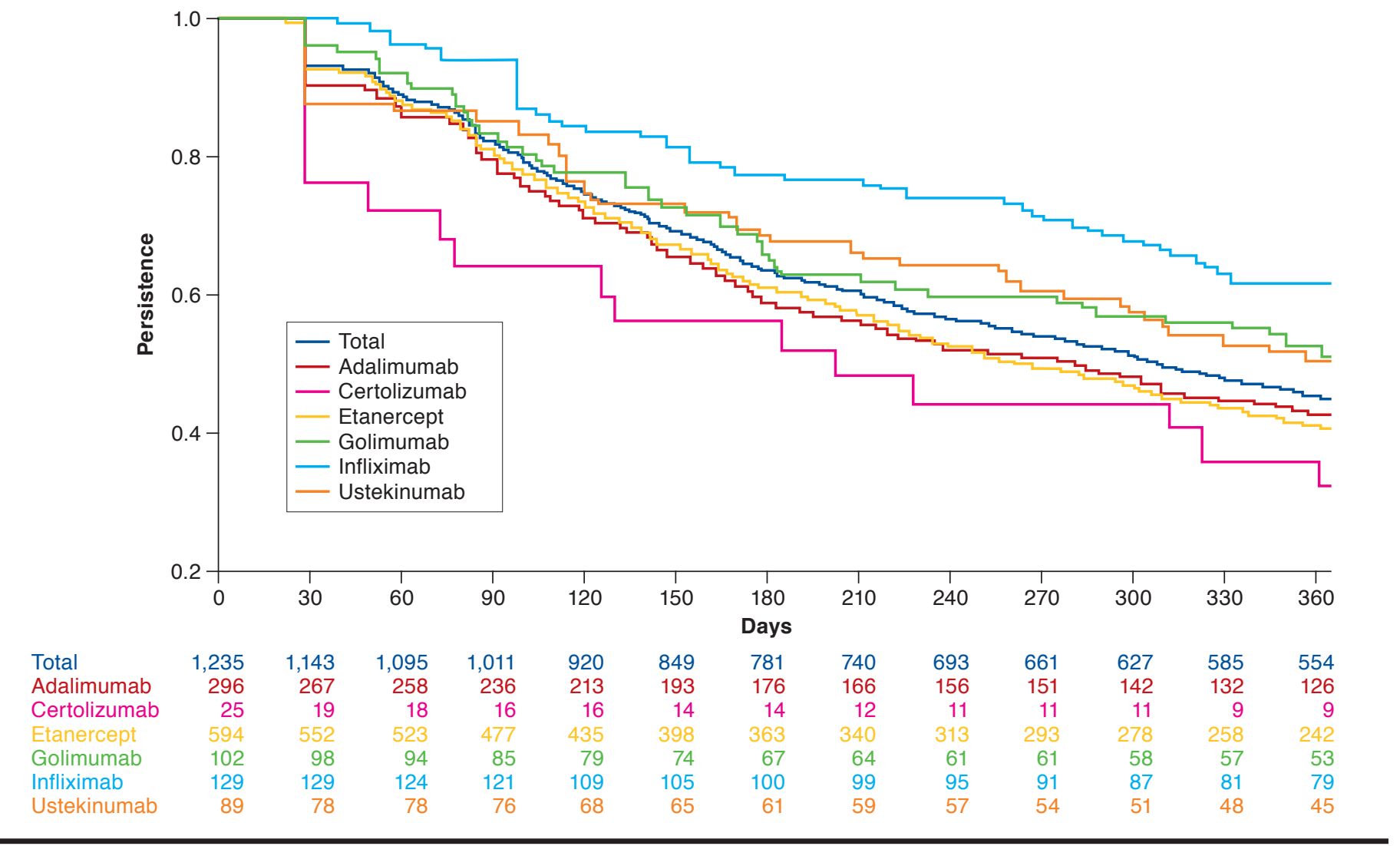

who initiated infliximab had the longest mean persistence (293 days), and patients who initiated certolizumab pegol had the shortest mean persistence (207 [146] days; Table 2 and Figure 1).

Overall, $44.5 \%$ of patients persisted with the index biologic for $\geq 12$ months (Table 2); infliximab had the highest percentage of patients persistent at 12 months (61.2\%) and certolizumab pegol had the lowest (32.0\%). Among the total patients, 55.5\% were not persistent with the index biologic at 12 months: $26.8 \%$ discontinued without switching or restarting, 5.8\% discontinued and restarted the index biologic, and 22.9\% switched to a different biologic (Table 2). Among patients who switched to a different biologic, the mean (95\% confidence interval) time to switch was 177.4 (166.6-188.2) days (approximately 6 months; Table 2). The most common biologic therapy that patients were switched to was adalimumab (48.4\%), followed by etanercept (14.5\%; Figure 2).

\section{Therapy Modifications Among Patients Who Persisted with Their Index Biologic for $>\mathbf{9 0}$ Days}

Among the 1,010 patients who persisted with their index biologic for $>90$ days, $92.1 \%$ of patients had received $\geq 1$ of the following medications during the 12-month baseline period: $60.7 \%$ received corticosteroids, 55.2\% NSAIDs, 51.1\% csDMARDs, and $47.5 \%$ opioids. During the add-on period (the period from 90 days after the index date to the end of persistence or 12 months), $45.6 \%$ of patients initiated $\geq 1$ adjunctive medication. The most commonly initiated adjunctive medications were corticosteroids (22.0\%), followed by opioids (17.1\%), NSAIDs (12.9\%), and csDMARDs (5.3\%; Table 3). Ustekinumab had the highest rate of patients initiating an adjunctive medication (59.2\%), followed by infliximab (51.2\%), certolizumab pegol (50.0\%), golimumab (45.9\%), adalimumab (44.9\%), and etanercept (42.0\%).

Of these 1,010 patients, $9.6 \%$ had a dose escalation of the index biologic in the 12-month post-index period. Among the 121 patients who received the intravenously administered TNFi infliximab as their index biologic, 33.9\% had a dose escalation. Of the 813 patients with a subcutaneously administered TNFi as their index biologic, $6.4 \%$ had a dose escalation; etanercept had the highest rate of dose escalation (8.4\%), followed by certolizumab pegol (6.2\%), adalimumab (4.7\%), and golimumab (0.0\%). Among the 76 patients receiving ustekinumab 


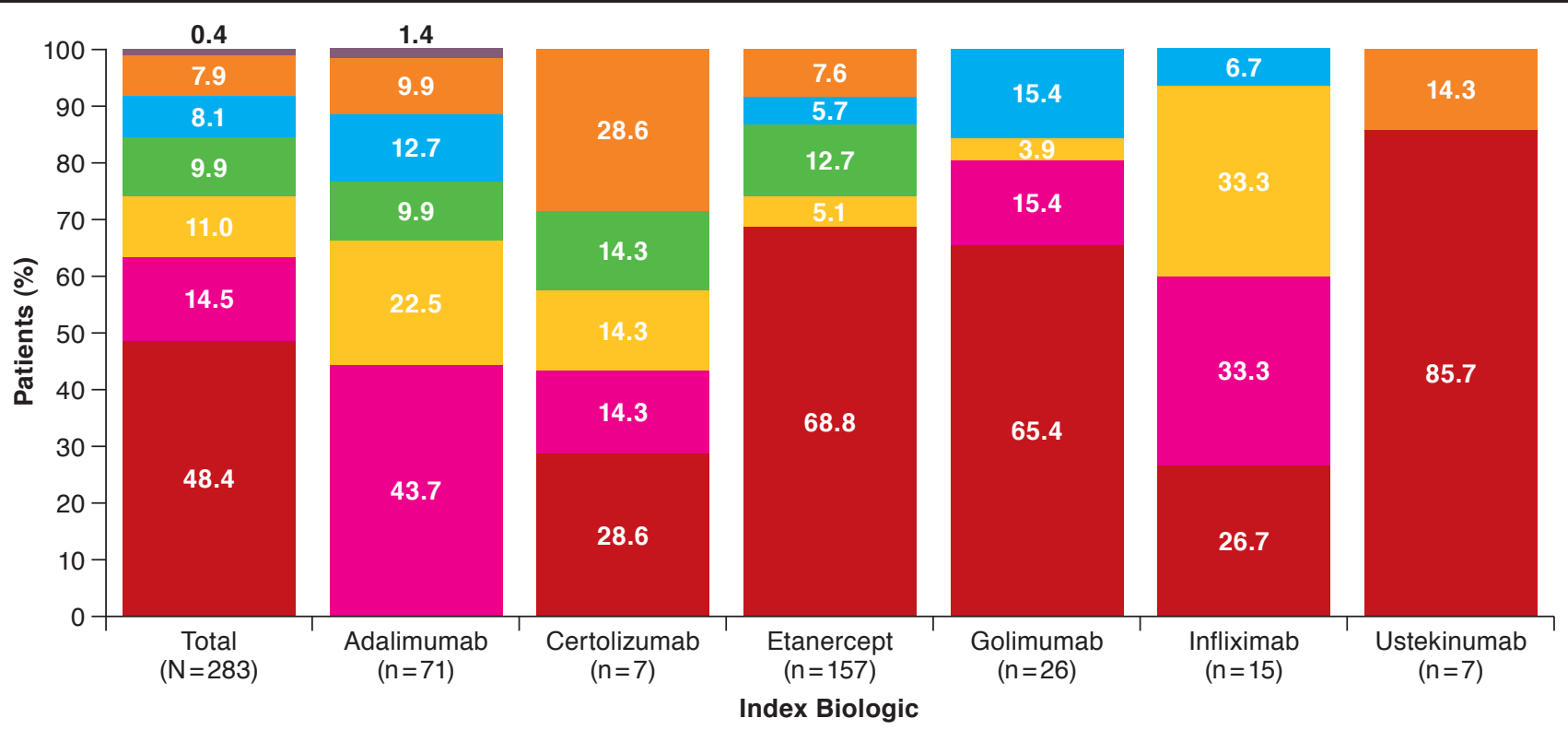

Subsequent Biologic

Adalimumab Certolizumab pegol Etanercept Golimumab Infliximab Ustekinumab $\quad$ Secukinumab

ancludes patients who discontinued the index biologic and then switched to a different biologic.

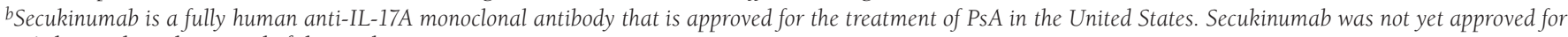
PsA during the index period of this study.

IL = interleukin; PSA = psoriatic arthritis.

(subcutaneously administered), 5.3\% had a dose escalation. The mean (SD) number of days from index date to dose escalation was 192 (75) days.

\section{Discussion}

In this descriptive, administrative claims-based study, the majority of patients with PsA (55.5\%) discontinued their index biologic before 12 months, with a mean persistence of approximately 8 months. Among patients who persisted for $>90$ days, $45.6 \%$ received $\geq 1$ adjunctive medication during the period from 90 days after the index date to the end of persistence with the index biologic or 12 months, and 9.6\% had a dose escalation of the index biologic in the immediate 12-month post-index period.

The percentage of patients persistent at 12 months in this study (44.5\%) was lower than in other studies; previous U.S. studies showed 12-month persistence with biologic therapy ranging from $51 \%$ to $66 \%$ in patients with PsA..$^{32,34,35,41}$ One reason for the difference in persistence among the studies may be related to varying severity of comorbidities in the patients studied. Comorbidities may affect the safety of and response to biologic therapy and lead to discontinuation or switching of the biologic. ${ }^{42}$
In the present study, the mean baseline Quan-Charlson Comorbidity Index score was 0.73 as opposed to 0.52 in the study by Zhang et al. (2014), which showed a 12-month persistence of 54\%. ${ }^{34}$ Furthermore, the higher comorbidity burden observed in patients with certolizumab pegol as their index biologic may have contributed to their lower persistence relative to patients receiving other biologics. Lower 12-month persistence with biologic treatment in the present study may also be related to changes in costs or insurance coverage of biologics, health care provider prescribing patterns, and patient preference, or to lack of efficacy, adverse effects, and insufficient pain control. . $^{30,32,38}$

The proportion of patients who switched biologics in the present study (22.9\%) was similar to other studies.34,35,38 Although this study did not capture the reason patients switched biologics, a previous study of patients with PsA showed that adverse effects and lack of efficacy were the most common reasons patients switched their TNFi. ${ }^{43}$ Additionally, it is possible that some patients may discontinue biologic therapy because of minimal symptoms of PsA, although it is unlikely that the high proportion of patients switching biologic therapy or initiating adjunctive anti-inflammatory or pain medications had adequate symptom control. 


\begin{tabular}{|c|c|c|c|c|c|c|c|}
\hline \multirow[b]{2}{*}{ Adjunctive Medication, n (\%) } & \multirow[b]{2}{*}{$\begin{array}{c}\text { Total } \\
(\mathrm{N}=1,010)\end{array}$} & \multicolumn{4}{|c|}{ TNFi SC } & \multirow{2}{*}{$\begin{array}{l}\text { TNFi IV } \\
\text { Infliximab } \\
(\mathrm{n}=121)\end{array}$} & \multirow{2}{*}{$\begin{array}{c}\text { Anti-IL-12/23 } \\
\text { SC } \\
\begin{array}{c}\text { Ustekinumab } \\
(n=76)\end{array}\end{array}$} \\
\hline & & $\begin{array}{l}\text { Etanercept } \\
(\mathrm{n}=476)\end{array}$ & $\begin{array}{l}\text { Adalimumab } \\
(\mathbf{n}=236)\end{array}$ & $\begin{array}{c}\text { Certolizumab } \\
\text { pegol } \\
(\mathrm{n}=16)\end{array}$ & $\begin{array}{l}\text { Golimumab } \\
(\mathrm{n}=85)\end{array}$ & & \\
\hline Any medication & $460(45.6)$ & $200(42.0)$ & $106(44.9)$ & $8(50.0)$ & $39(45.9)$ & $62(51.2)$ & $45(59.2)$ \\
\hline Corticosteroid & $222(22.0)$ & $90(18.9)$ & $52(22.0)$ & $6(37.5)$ & $20(23.5)$ & $37(30.6)$ & $17(22.4)$ \\
\hline Opioid & $173(17.1)$ & $66(13.9)$ & $44(18.6)$ & $2(12.5)$ & $14(16.5)$ & $20(16.5)$ & $27(35.5)$ \\
\hline NSAID & $130(12.9)$ & $63(13.2)$ & $29(12.3)$ & $2(12.5)$ & $11(12.9)$ & $14(11.6)$ & $11(14.5)$ \\
\hline csDMARDa & $54 \quad(5.3)$ & $27 \quad(5.7)$ & $9 \quad(3.8)$ & $1 \quad(6.2)$ & $6 \quad(7.1)$ & $8 \quad(6.6)$ & $3(3.9)$ \\
\hline Antidepressant & $49 \quad(4.9)$ & $16 \quad(3.4)$ & $13 \quad(5.1)$ & $0 \quad(0.0)$ & $5 \quad(5.9)$ & $8 \quad(6.6)$ & $7 \quad(9.2)$ \\
\hline Anxiolytic & $48 \quad(4.8)$ & $18 \quad(3.8)$ & $11 \quad(4.7)$ & $0 \quad(0.0)$ & $5 \quad(5.9)$ & $10 \quad(8.3)$ & $4 \quad(5.3)$ \\
\hline Topical analgesic & $31 \quad(3.1)$ & $14 \quad(2.9)$ & $9 \quad(3.8)$ & $0 \quad(0.0)$ & $1 \quad(1.2)$ & $4 \quad(3.3)$ & $3(4.0)$ \\
\hline Sleep aid & $22 \quad(2.2)$ & $10 \quad(2.1)$ & $6 \quad(2.5)$ & $\begin{array}{ll}0 & (0.0) \\
\end{array}$ & $1 \quad(1.2)$ & $4 \quad(3.3)$ & $1 \quad(1.3)$ \\
\hline tsDMARDb & $11 \quad(1.1)$ & $6 \quad(1.3)$ & $1 \quad(0.4)$ & $\begin{array}{ll}0 & (0.0) \\
\end{array}$ & $2 \quad(2.4)$ & $\begin{array}{ll}0 & (0.0) \\
\end{array}$ & $2 \quad(2.6)$ \\
\hline \multicolumn{8}{|c|}{$\begin{array}{l}\text { aIncluded auranofin, aurothioglucose, azathioprine, cyclosporine, gold sodium, hydroxychloroquine, leflunomide, methotrexate, and sulfasalazine. } \\
\text { 'Included apremilast and tofacitinib. } \\
\text { cSDMARD = conventional synthetic disease-modifying antirheumatic drug; IL=interleukin; IV=intravenous; NSAID =nonsteroidal anti-inflammatory drug; } \\
S C=\text { subcutaneous; TNFi = tumor necrosis factor inhibitor; tsDMARD = targeted synthetic disease-modifying antirheumatic drug. }\end{array}$} \\
\hline
\end{tabular}

High rates of discontinuation and switching of biologic therapies, along with high rates of dose escalation, suggest a high frequency of suboptimal biologic experience in patients with PsA. The reasons for more frequent dose escalations are unclear, but possible reasons include dosing instructions, caution in administering the initial doses, increased flexibility of IV infusion, and insurance approval policies. Furthermore, PsA is a heterogeneous disease, and treatment responses to biologics can vary substantially between patients.

More research to guide patients and health care providers in making decisions about choosing first- and subsequent-line biologics is needed. In addition, more research is needed to evaluate differences between lines of TNFi therapies. A recent systematic literature review of 18 real-world studies, most of which were outside the United States, reported limited evidence comparing different lines of therapy; however, first-line TNFi therapy was found to yield better results than secondline TNFi therapy, and significant differences were observed between second- and third-line TNFis. ${ }^{44}$ Moreover, recent studies have shown that biologic-naive patients were more persistent with their first biologic than were patients with a history of biologic use. ${ }^{38,45}$ Additional treatment options may be beneficial to address the heterogeneity of the disease and patients' responses to treatment.

To our knowledge, this study is one of a limited number that have examined adjunctive medications for patients with PsA initiating a biologic therapy. In the findings presented here, a large percentage of patients modified their treatment. Use of adjunctive DMARDs was similar between this study and previous studies; however, the previous studies only evaluated adjunctive DMARDs and not other additional medications. ${ }^{34,38}$ Notably, the majority of claims for adjunctive medications in this study were for treatment of pain and inflammation (corticosteroids, 22\% of patients; opioids, 17\%; NSAIDS, 13\%), which suggests that some patients have inadequate disease control while receiving biologic therapy.

Similarly, a previous study that compared use of concomitant medications during the 12 months before and after initiating a biologic found that $46.1 \%$ of patients were receiving pain medication at 12 months after starting biologic therapy. ${ }^{35}$ Currently, no recommendations exist for the use of adjunctive medications for patients with PsA who have an inadequate response to biologics alone or with the addition of csDMARDs. It is also important to note that long-term administration of systemic corticosteroids is neither recommended nor supported by evidence for patients with PsA, but short-term use may be indicated for rescue therapy. ${ }^{46}$

In addition to pain and anti-inflammatory medications, 9.7\% of patients received either an antidepressant or anxiolytic. More research is needed to better understand why some patients with PsA require additional pain and mental health medications.

Although the reasons for dose escalation are not entirely understood, they may involve the availability of insurance approval for dose escalations and caution in administering the initial doses. Notably, a larger proportion of patients receiving an intravenously administered biologic had dose escalation than patients receiving a subcutaneously administered biologic. Infliximab also had the highest 12-month persistence in the present study. 
The relationship between dose escalation and persistence is unclear. Dose escalation requires time for insurance approval and may provide more effective dosing; therefore, these factors may have contributed to longer persistence. In addition, patients receiving infliximab may have had higher rates of persistence because infliximab is administered by a health care provider. Persistence may also be influenced by the administration of infliximab every 8 weeks as opposed to every 1-4 weeks with subcutaneously administered biologics.

With the emergence of additional non-TNFi treatment options for PsA, future studies will be needed to examine the impact of these newer therapies on treatment patterns and therapy modifications in patients with PsA.

The strengths of the present study include the use of data from a large database covering all regions of the United States, which provides valuable real-world information. In addition, these findings expand on previous studies by examining the use of adjunctive medications in patients receiving a biologic for PsA.

\section{Limitations}

This study was limited by its retrospective design and includes observational analyses of administrative claims databases with descriptive findings only. The claims data also did not capture the reasons for switching, discontinuation, dose escalation, or adding adjunctive therapy; thus, it is unknown how various factors influence these treatment decisions/patterns. Because the study was limited to 12 months, longer-term treatment patterns are unknown.

Furthermore, this study was limited to patients with commercial health coverage or Medicare Advantage, and 49\% of patients were from 1 U.S. region (South); it is unclear if these findings can be extended to patients in all regions of the United States and to those with Medicaid or no insurance. Finally, this study could not consider the potential effects of rebates, discounts, or other price concessions on choice of biologic therapy, and utilization rates may differ based on the formulary of each payer/employer group.

\section{Conclusions}

The majority of patients with PsA discontinued their index biologic (TNFi or anti-IL-12/23 inhibitor) before 12 months, and mean persistence was approximately 8 months. Nearly half of patients initiated an adjunctive medication, many of which were pain and anti-inflammatory medications. Insufficient control of symptoms may lead patients to discontinue biologic therapy, which can contribute to disease progression. Further research is necessary to routinely monitor patient outcomes; to understand the reasons patients with PsA discontinue, switch, or modify biologic therapy; and to assess the impact of insufficient control of pain and inflammation.

\section{Authors}

JESSICA A. WALSH, MD, University of Utah School of Medicine and Salt Lake City Veterans Affairs Medical Center, Salt Lake City, Utah. OLUWAKAYODE ADEJORO, MD, MPH, and BENJAMIN CHASTEK, MS, Optum, Eden Prairie, Minnesota. JACQUELINE B. PALMER, PharmD, and PETER HUR, PharmD, MBA, Novartis Pharmaceuticals, East Hanover, New Jersey.

AUTHOR CORRESPONDENCE: Jessica Walsh, MD, University of Utah School of Medicine, 50 N. Medical Dr., Salt Lake City, UT 84132. Tel.: 801.581.7724; E-mail: Jessica.walsh@hsc.utah.edu.

\section{DISCLOSURES}

This study was sponsored by Novartis Pharmaceuticals. Optum was commissioned by Novartis to conduct this study, but employment was not contingent on results of the study. Walsh is a paid consultant for Novartis. Adejoro was an employee of Optum at the time of the study and writing of the manuscript. Chastek is an employee of Optum. Palmer and Hur are employees of Novartis.

Results of this study were presented as an abstract and poster at the Academy of Managed Care Pharmacy Nexus 2017; October 16-19, 2017; Dallas, TX; and the EULAR 2017 Annual European Congress of Rheumatology; June 14-17, 2017; Madrid, Spain.

\section{ACKNOWLEDGMENTS}

Writing assistance for this manuscript was furnished by Nicola Gillespie, DVM, of Health Interactions, which was funded by Novartis Pharmaceuticals.

\section{REFERENCES}

1. Cantini F, Niccoli L, Nannini C, Kaloudi O, Bertoni M, Cassara E. Psoriatic arthritis: a systematic review. Int J Rheum Dis. 2010;13(4):300-17. 2. Huynh D, Kavanaugh A. Psoriatic arthritis: current therapy and future approaches. Rheumatology (Oxford). 2015;54(1):20-28

3. Lee S, Mendelsohn A, Sarnes E. The burden of psoriatic arthritis: a literature review from a global health systems perspective. P T. 2010;35(12):680-89. 4. Coates LC, Kavanaugh A, Mease PJ, et al. Group for research and assessment of psoriasis and psoriatic arthritis 2015 treatment recommendations for psoriatic arthritis. Arthritis Rheumatol. 2016;68(5):1060-71.

5. Gladman DD. Clinical features and diagnostic considerations in psoriatic arthritis. Rheum Dis Clin North Am. 2015;41(4):569-79.

6. Ahmed N, Prior JA, Chen Y, Hayward R, Mallen CD, Hider SL. Prevalence of cardiovascular-related comorbidity in ankylosing spondylitis, psoriatic arthritis and psoriasis in primary care: a matched retrospective cohort study. Clin Rheumatol. 2016;35(12):3069-73.

7. Haddad A, Zisman D. Comorbidities in patients with psoriatic arthritis. Rambam Maimonides Med J. 2017;8(1):e0004. Available at: https://www.rmmj. org.il/userimages/619/1/PublishFiles/647Article.pdf. Accessed March 2, 2018.

8. Greenberg JD, Palmer JB, Li Y, Herrera V, Tsang Y, Liao M. Healthcare resource use and direct costs in patients with ankylosing spondylitis and psoriatic arthritis in a large U.S. cohort. J Rheumatol. 2016;43(1):88-96.

9. Ogdie A, Schwartzman S, Eder L, et al. Comprehensive treatment of psoriatic arthritis: managing comorbidities and extraarticular manifestations. J Rheumatol. 2014;41(11):2315-22.

10. Husni ME. Comorbidities in psoriatic arthritis. Rheum Dis Clin North Am. 2015;41(4):677-98.

11. Gossec L, Smolen JS. Treatment of psoriatic arthritis: management recommendations. Clin Exp Rheumatol. 2015;33(5 Suppl 93):S73-7.

12. Kang EJ, Kavanaugh A. Psoriatic arthritis: latest treatments and their place in therapy. Ther Adv Chronic Dis. 2015;6(4):194-203. 
13. Gossec L, Smolen JS, Ramiro S, et al. European League Against Rheumatism (EULAR) recommendations for the management of psoriatic arthritis with pharmacological therapies: 2015 update. Ann Rheum Dis. 2016;75(3):499-510.

14. Mease PJ, Gladman DD, Ritchlin CT, et al. Adalimumab for the treatment of patients with moderately to severely active psoriatic arthritis: results of a double-blind, randomized, placebo-controlled trial. Arthritis Rheum. 2005;52(10):3279-89.

15. Antoni C, Krueger GG, de Vlam K, et al. Infliximab improves signs and symptoms of psoriatic arthritis: results of the IMPACT 2 trial. Ann Rheum Dis. 2005;64(8):1150-57.

16. Gladman DD, Mease PJ, Ritchlin CT, et al. Adalimumab for long-term treatment of psoriatic arthritis: forty-eight week data from the adalimumab effectiveness in psoriatic arthritis trial. Arthritis Rheum. 2007;56(2):476-88.

17. Kavanaugh A, McInnes I, Mease P, et al. Golimumab, a new human tumor necrosis factor alpha antibody, administered every four weeks as a subcutaneous injection in psoriatic arthritis: twenty-four-week efficacy and safety results of a randomized, placebo-controlled study. Arthritis Rheum. 2009;60(4):976-86

18. Mease PJ, Fleischmann R, Deodhar AA, et al. Effect of certolizumab pegol on signs and symptoms in patients with psoriatic arthritis: 24-week results of a phase 3 double-blind randomised placebo-controlled study (RAPID-PsA). Ann Rheum Dis. 2014;73(1):48-55.

19. Keystone E, Landewe R, van Vollenhoven R, et al. Long-term safety and efficacy of certolizumab pegol in combination with methotrexate in the treatment of rheumatoid arthritis: 5-year results from the RAPID 1 trial and open-label extension. Ann Rheum Dis. 2014;73(12):2094-100.

20. Kavanaugh A, van der Heijde D, McInnes IB, et al. Golimumab in psoriatic arthritis: one-year clinical efficacy, radiographic, and safety results from a phase III, randomized, placebo-controlled trial. Arthritis Rheum. 2012;64(8):2504-17.

21. Mease PJ, Kivitz AJ, Burch FX, et al. Etanercept treatment of psoriatic arthritis: safety, efficacy, and effect on disease progression. Arthritis Rheum. 2004;50(7):2264-72

22. Gottlieb A, Menter A, Mendelsohn A, et al. Ustekinumab, a human interleukin 12/23 monoclonal antibody, for psoriatic arthritis: randomised, doubleblind, placebo-controlled, crossover trial. Lancet. 2009;373(9664):633-40.

23. Mease P, Genovese MC, Gladstein G, et al. Abatacept in the treatment of patients with psoriatic arthritis: results of a six-month, multicenter, randomized, double-blind, placebo-controlled, phase II trial. Arthritis Rheum. 2011;63(4):939-48.

24. Mease PJ, Gottlieb AB, van der Heijde D, et al. Efficacy and safety of abatacept, a T-cell modulator, in a randomised, double-blind, placebocontrolled, phase III study in psoriatic arthritis. Ann Rheum Dis. 2017;76(9):1550-58.

25. McInnes IB, Mease PJ, Kirkham B, et al. Secukinumab, a human antiinterleukin-17A monoclonal antibody, in patients with psoriatic arthritis (FUTURE 2): a randomised, double-blind, placebo-controlled, phase 3 trial. Lancet. 2015;386(9999):1137-46.

26. Strand V, Mease P, Gossec L, et al. Secukinumab improves patientreported outcomes in subjects with active psoriatic arthritis: results from a randomised phase III trial (FUTURE 1). Ann Rheum Dis. 2017;76(1):203-07. 27. Mease PJ, van der Heijde D, Ritchlin CT, et al. Ixekizumab, an interleukin-17A specific monoclonal antibody, for the treatment of biologic-naive patients with active psoriatic arthritis: results from the 24-week randomised, double-blind, placebo-controlled and active (adalimumab)-controlled period of the phase III trial SPIRIT-P1. Ann Rheum Dis. 2017;76(1):79-87.

28. Nash P, Kirkham B, Okada M, et al. Ixekizumab for the treatment of patients with active psoriatic arthritis and an inadequate response to tumour necrosis factor inhibitors: results from the 24-week randomised, doubleblind, placebo-controlled period of the SPIRIT-P2 phase 3 trial. Lancet. 2017;389(10086):2317-27.
29. Smolen JS, Braun J, Dougados M, et al. Treating spondyloarthritis, including ankylosing spondylitis and psoriatic arthritis, to target: recommendations of an international task force. Ann Rheum Dis. 2014;73(1):6-16. 30. Merola JF, Lockshin B, Mody EA. Switching biologics in the treatment of psoriatic arthritis. Semin Arthritis Rheum. 2017;47(1):29-37.

31. Garrido-Cumbrera M, Hillmann O, Mahapatra R, et al. Improving the management of psoriatic arthritis and axial spondyloarthritis: roundtable discussions with healthcare professionals and patients. Rheumatol Ther. 2017:4(2):219-31.

32. Bonafede M, Fox KM, Watson C, Princic N, Gandra SR. Treatment patterns in the first year after initiating tumor necrosis factor blockers in realworld settings. Adv Ther. 2012;29(8):664-74.

33. Schwartzman S, Li Y, Zhou H, Palmer JB. Economic impact of biologic utilization patterns in patients with psoriatic arthritis. Clin Rheumatol. 2017;36(7):1579-88.

34. Zhang HF, Gauthier G, Hiscock R, Curtis JR. Treatment patterns in psoriatic arthritis patients newly initiated on oral nonbiologic or biologic disease-modifying antirheumatic drugs. Arthritis Res Ther. 2014;16(4):420.

35. Zhu B, Edson-Heredia E, Gatz JL, Guo J, Shuler CL. Treatment patterns and health care costs for patients with psoriatic arthritis on biologic therapy: a retrospective cohort study. Clin Ther. 2013;35(9):1376-85.

36. Yeaw J, Watson C, Fox KM, Schabert VF, Goodman S, Gandra SR. Treatment patterns following discontinuation of adalimumab, etanercept, and infliximab in a US managed care sample. Adv Ther. 2014;31(4):410-25.

37. Howe A, Eyck LT, Dufour R, Shah N, Harrison DJ. Treatment patterns and annual drug costs of biologic therapies across indications from the Humana commercial database. J Manag Care Spec Pharm. 2014;20(12):1236-44 Available at: https://www.jmcp.org/doi/10.18553/jmcp.2014.20.12.1236.

38. Palmer JB, Li Y, Herrera V, Liao M, Tran M, Ozturk ZE. Treatment patterns and costs for anti-TNFa biologic therapy in patients with psoriatic arthritis. BMC Musculoskelet Disord. 2016;17:261.

39. Quan H, Li B, Couris CM, et al. Updating and validating the Charlson comorbidity index and score for risk adjustment in hospital discharge abstracts using data from 6 countries. Am J Epidemiol. 2011;173(6):676-82.

40. Bayliss EA, Ellis JL, Shoup JA, Zeng C, McQuillan DB, Steiner JF. Association of patient-centered outcomes with patient-reported and ICD-9-based morbidity measures. Ann Fam Med. 2012;10(2):126-33.

41. Chastek B, White J, Van Voorhis D, Tang D, Stolshek BS. A retrospective cohort study comparing utilization and costs of biologic therapies and JAK inhibitor therapy across four common inflammatory indications in adult US managed care patients. Adv Ther. 2016;33(4):626-42.

42. Ogdie A, Eder L. Improving cardiovascular health and metabolic comorbidities in patients with psoriatic arthritis. Int J Clin Rheumtol. 2015;10(6):451-59.

43. Glintborg B, Ostergaard M, Krogh NS, et al. Clinical response, drug survival, and predictors thereof among 548 patients with psoriatic arthritis who switched tumor necrosis factor $\alpha$ inhibitor therapy: results from the Danish nationwide DANBIO registry. Arthritis Rheum. 2013;65(5):1213-23.

44. Reddy SM, Crean S, Martin AL, Burns MD, Palmer JB. Real-world effectiveness of anti-TNF switching in psoriatic arthritis: a systematic review of the literature. Clin Rheumatol. 2016;35(12):2955-66.

45. Harrold LR, Stolshek BS, Rebello S, et al. Impact of prior biologic use on persistence of treatment in patients with psoriatic arthritis enrolled in the U.S. Corrona registry. Clin Rheumatol. 2017;36(4):895-901.

46. D'Angelo S, Tramontano G, Gilio M, Leccese P, Olivieri I. Review of the treatment of psoriatic arthritis with biological agents: choice of drug for initial therapy and switch therapy for non-responders. Open Access Rheumatol. 2017:9:21-28. 
Treatment Patterns Among Patients with Psoriatic Arthritis Treated with a Biologic in the United States: Descriptive Analyses from an Administrative Claims Database

\section{APPENDIX A Observation Period Schematic}
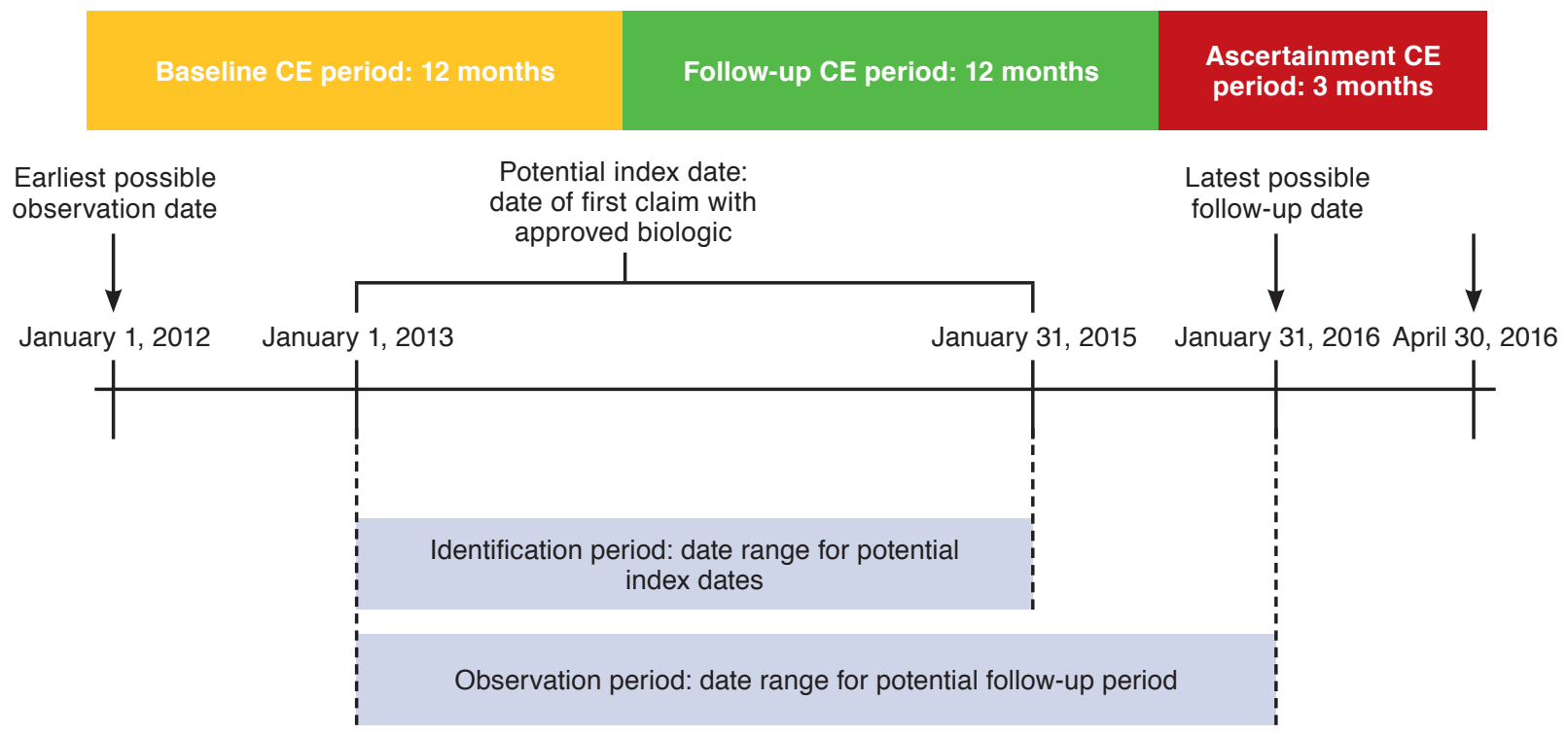

aPatients were required to have $\geq 2$ non-rule-out diagnoses for PsA during the study. The 2 claims had to be $\geq 30$ days apart, and the first claim had to be on the index date or during the baseline period.

$C E=$ continuous enrollment; $P s A=$ psoriatic arthritis 
Treatment Patterns Among Patients with Psoriatic Arthritis Treated with a Biologic in the United States: Descriptive Analyses from an Administrative Claims Database

\section{APPENDIX B Patient Selection Flowchart}

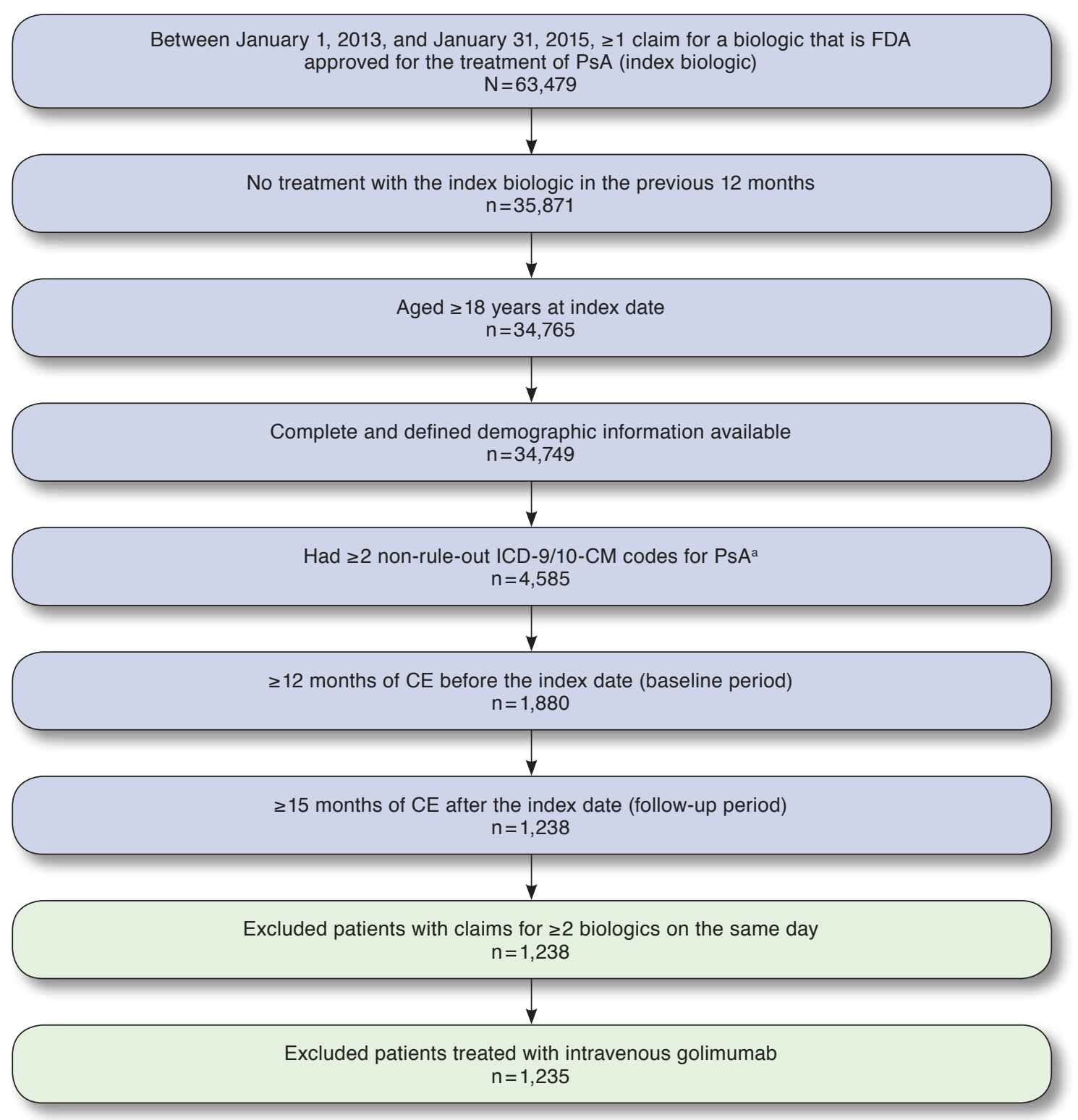

aThe 2 ICD-9/10-CM codes had to be $\geq 30$ days apart and recorded during the period 12 months before and after the index date; the first claim had to be on the index date or during the baseline period.

$C E=$ continuous enrollment $; F D A=U . S$. Food and Drug Administration; ICD-9/10-CM=International Classification of Diseases, Ninth/Tenth Revision, Clinical Modification; PSA=psoriatic arthritis. 